\title{
Campo de edição
}

\author{
DORA PORTO \\ Pesquisadora Independente, Brasília/DF, Brasil \\ doraporto@gmail.com
}

DOI 10.11606/issn.2316-9133.v30i1pe185628

resumo $\mathrm{O}$ ensaio reflete sobre a prática de editora científica, realizada pela autora ao longo de 12 anos em duas revistas científicas no campo da bioética no Brasil. Apresenta em linhas gerais sugestões aspectos pessoais e profissionais considerados importantes ao exercício da função. Objetiva fornecer elementos para que estudantes das áreas das Ciências Sociais possam conhecer e optar por esta atividade.

palavras-chave Ciências Sociais. Comunicação Acadêmica. Editor Científico. Periódico. Pesquisa de Campo.

\section{The field of scientific publishing}

abstract The essay reflects on the practice of scientific publisher, carried out by the author over 12 years in two scientific journals in the field of bioethics in Brazil. In general, it presents suggestions for personal and professional aspects considered important to the exercise of the function. It aims to provide elements so that students in the areas of Social Sciences can get to know and choose this activity.

keywords Social Sciences. Scholarly Communication. Scientific Editor. Journal. Field Research.

\section{El campo de la edición científica}

resumen El ensayo reflexiona sobre la práctica de la edición, realizada por la autora al largo de 12 años en dos revistas científicas en el campo de la bioética en Brasil. Presenta sugerencias sobre aspectos personales y profesionales que se consideran importantes para el ejercicio de la función. Tiene como objetivo aportar elementos para que los estudiantes de las áreas de Ciencias Sociales puedan conocer y elegir esta actividad.

palabras clave Ciencias Sociales. Comunicación Académica. Editor científico. Periódico. Investigación de Campo.

\section{Introdução}


Este texto pretende delinear aquilo que considero os principais atributos para o desempenho da função de editora científica, compreendidos a partir da minha experiência em dois periódicos brasileiros no campo da bioética ao longo de 15 anos. O processo que levou a adotar a área da Saúde Coletiva como campo de pesquisa, como as dificuldades e impasses da busca interdisciplinar, foi descrito em publicação destinada a tratar das questões éticas na pesquisa social (Porto, 2010). Sem discutir aspectos específicos das normas e critérios de publicação atualmente vigentes no Brasil em cada área do conhecimento, reporto a experiência e as escolhas como editora, considerando especificamente a formação antropológica e a pósgraduação em bioética e saúde coletiva.

Sem generalizar o processo, reitero que este relato é um estudo de caso, apresentado como narrativa em primeira pessoa, de maneira coloquial. Não apresento ou discuto aqui nenhum aspecto administrativo ou logístico do processo editorial, intrinsecamente condicionados pelo contexto, financiamento e demais características administrativas e operacionais dos periódicos.

Mesmo entendendo a importância nesse momento de dar visibilidade às questões de gênero, optei por utilizar nesse relato o masculino singular, em autor e editor, considerando que as leitoras, leitorxs e leitores irão entender que este relato pretende apenas colaborar para que se entenda melhor a atividade.

\section{Antecedentes}

O mais impressionante xingamento que ouvi na infância foi A-NAL-FA-BE-TA. As letras escandidas e maiúsculas reproduzem meu horror diante deste epíteto. Como em todas às vezes nas quais havia desavenças corri para minha mãe para confirmar a inverdade da acusação. Mas, surpreendi-me ao constatar que ela concordava: "É filha, você é analfabeta". De repente o chão se abriu, meu sangue gelou e me senti a mais reles das criaturas.

Até então, quando era taxada de "chata", "feia" e "boba" tinha podido contar com o indubitável apoio materno, me assegurando que nada daquilo era verdade. Mas desta feita a coisa mudava de figura. Eu tinha - de fato - esse defeito que até aquele momento sequer tinha ouvido falar. Vendo minha consternação à beira das lágrimas, mamãe explicou que aquilo não seria para sempre; em breve eu iria à escola e aprenderia a ler, deixando aquela terrível condição.

De fato, poucos meses depois aprendi a ler como mágica. Do "vovô viu a uva” para frases inteiras foi um pequeno pulo, que dei com encanto e satisfação. Logo que dominei a arte de alinhavar as letras passei a ser leitora contumaz. Saber ler era ser independente. Podia ler quando queria, e quase tudo que me despertava a atenção, sem tutela.

Dos gibis a O Pasquim, das revistas aos livros, tudo me interessava. Ler se tornou uma segunda natureza. Acompanhando esse processo voraz, comecei também a escrever, imaginando histórias a partir de gravuras ou mesmo das solicitações de redação feitas pelos 
professores. Escrever, intuía, era tornar-me capaz que registrar histórias, de preservá-las incólumes no tempo. De ser a leitora mais assídua da biblioteca do colégio à mais furtiva esquadrinhadora das estantes do meu pai, passei a compor, editar e vender poesias, que no final da adolescência expressavam minha rebeldia. Frequentava sebos, livrarias e bibliotecas com a luxúria de amante; às vezes, apenas deslizar as mãos sobre as capas das obras que queria conhecer já provocava frisson, mesmo que o livro estivesse fora das possibilidades do meu bolso ou fosse escrito em idioma desconhecido.

Todo esse preâmbulo, que parece não ter qualquer relação com o tema deste texto, ilustra as qualidades que considero essenciais para ser editor. Para enveredar por essa trilha é preciso, antes de tudo, profundo amor pela leitura e pela escrita. Só a paixão pela palavra e a curiosidade para encontrar seus significados; o empenho para tentar alcançar a precisão na utilização dos termos; o desejo de transmitir a ideia exata; e o êxtase de atingir o objetivo da comunicação simples e direta, pode compensar a extrema dedicação inerente à tarefa. Um fazer solitário, meticuloso, cansativo, demorado e, muitas vezes, incompreendido e criticado.

\section{A arte do ofício}

Ao que eu saiba não há no Brasil graduação que habilite à tarefa de editar ou habilite a realizar edição científica. Cursos de curta duração, workshops, congressos, encontros e palestras organizados por instituições que avaliam e indexam periódicos acabam sendo as principais fontes de informação sobre o métier. As conversas com os seniores também são fonte de conhecimento sobre o que é e no que consiste a profissão. São essas trocas que dão "pistas" sobre quais caminhos seguir, as certificações que se deve priorizar e as escolha que se precisa fazer. É uma trilha que se segue tateando até porque há poucas décadas ainda não havia critérios definidos pelas plataformas de indexação e instâncias de avaliação acerca de aspectos como endogenia acadêmica, plágio, autoplágio, citação, paráfrase, quantidade ótima de artigos de pesquisa, periodicidade por área etc.

Além dessa dificuldade relativa à formação profissional é preciso considerar que não há apenas um tipo de trabalho editorial. No meio acadêmico o modelo operacional adotado pelo periódico condiciona atribuições e responsabilidades. Derivando da correspondência entre cientistas, nos séculos XVII e XVIII, as primeiras revistas científicas traziam relatos de campo e descobertas, permitindo a ampliação da divulgação dos avanços em todas as áreas. Tradicionalmente, as revistas eram feitas pelo editor, que avaliava o material recebido antes da publicação e, eventualmente, submetendo-o também à análise de outros integrantes da mesma sociedade científica que publicava o periódico (Merlo, 2012; Silva, 2019).

Com o gradativo aumento das áreas do saber, das publicações e dos artigos a elas submetidos, esse modelo passou a se revelar exaustivo para o editor e insuficiente para suprir a crescente demanda acadêmica. Assim, foi criado o corpo editorial, integrando estudiosos que, 
geralmente, são especialistas nos diversos aspectos e temas da área do periódico. Em geral, esse grupo, que trabalha como editores adjuntos, recebe e faz a primeira análise dos manuscritos submetidos e designa os pares que irão avaliá-lo, influenciando e tomando parte na decisão sobre a publicação do trabalho. Seja qual for a configuração e o trâmite editorial cabe ao editor científico da publicação a decisão final e, principalmente, a responsabilidade sobre tudo que é publicado.

Como não existe um processo de formação consolidado, o fazer do editor não está totalmente definido. Seu trabalho consiste em apenas aceitar ou rejeitar os artigos submetidos? No caso da não aceitação, é preciso explicar o porquê para os autores? O que pode o editor fazer com os trabalhos que têm potencial para publicação, mas que apresentam falhas na apresentação das ideias, deixam dúvidas quanto à metodologia, se equivocam nos resultados, têm erros ortográficos ou mesmo abusam de termos pernósticos? Dependendo do periódico esses trabalhos são sumariamente descartados, às vezes sem qualquer explicação ao autor, inibindo sua oportunidade de aprendizado. Pode-se inferir que o compromisso principal desses veículos é manter seu status como publicação ultrasseletiva, utilizando credenciais vetustas para induzir a reverência nos leitores, associando-a à ideia de qualidade.

Entretanto, tal escolha tende a desconsiderar um objetivo importante da publicação científica, relacionado ao aspecto didático, inerente aos processos de conhecer e pensar. É necessário dominar a forma escrita para delinear, escrever, revisar, conferir o trabalho científico a fim de submetê-lo à avaliação por um periódico. Ajudar estudantes, professores e pesquisadores a serem capazes de exprimir com concisão e objetividade suas ideias faz parte do trabalho do editor, tanto porque tais qualidades nem sempre são aprendidas na academia quanto porque é mesmo difícil avaliar a própria produção.

Portanto, considero que apontar caminhos, sugerir ideias e aprimorar a forma de apresentá-las, faz parte da tarefa de editar. Quando é o caso, deve-se levar aos autores a conhecer novos parâmetros da área de estudo, como ocorreu em relação à bioética, por exemplo. Disseminada como sendo parte da Filosofia, a bioética foi incorporada à dinâmica hospitalar na forma de comitês e juntas, tornando-se conhecida principalmente pela teoria dos quatro princípios (beneficência, não-maleficência, justiça e autonomia) (Beauchamp e Childress, 2002). Até o início do século XXI estes parâmetros, denominados de princípios, eram considerados "A" bioética e aplicados somente no âmbito hospitalar e na pesquisa.

Nesse contexto, alguns tendiam a considerarem-na ciência, buscando assim conferir credibilidade. Apenas em 2005 foi aprovada pela Organização das Nações Unidas para a Educação, a Ciência e a Cultura (Unesco) a Declaração Universal sobre Bioética e Direitos Humanos (Unesco, 2005), que incorporando princípios dos Direitos Humanos ampliou a área de atuação da bioética, englobando a dimensão social e transformando-a em campo transdisciplinar de produção de saberes. A mudança atende à necessidade de utilizar ferramentas 
analíticas que possam responder aos dilemas de Saúde na sociedade, que é onde ocorre o adoecimento.

Sem diminuir a força da disciplina como instrumento para analisar o poder e as iniquidades, tal transformação aniquilou definitivamente a pretensão de ser ciência, porque ainda que trabalhe com fatos a bioética discute valores e moralidades, sendo mais afeita às Humanidades do que à área biomédica. Em decorrência a Medicina passou a ser o lócus dos estudos, de caráter inter e, especialmente, transdisciplinares. A incorporação dos Direitos Humanos permitiu que outras áreas do conhecimento pudessem se apropriar das ferramentas da bioética em suas análises e a própria bioética também se expandiu deixando de ser uma área (da Medicina ou da Filosofia) transmutando-se em campo (Bourdieu, 2012) no qual têm lugar de fala outras Ciências da Saúde, as Ciências Sociais e o Direito. Acredito que esta mudança, que reiteradamente apontei na edição inicial de cada trabalho recebido, contribuiu para divulgar a nova e mais abrangente visão da bioética. A meu ver, esse tipo de contribuição conceitual também faz parte das atividades editoriais.

Abrir mão da função pedagógica do periódico científico parece pedante e pouco produtivo. Acho que desperdiça um relevante instrumento capaz de aprimorar a formação acadêmica e profissional. Assim, outro atributo que me parece indispensável à atividade em países como o Brasil é estimular a formação, facilitando a comunicação entre autores e leitores, por meio de incentivo à adoção de linguagem acessível e direta, capaz de transmitir ideias e conceitos e não apenas emular a pretensa superioridade intelectual do autor. Embora haja pessoas que ainda considerem elegante escrever de maneira complicada e quase ininteligível, com parágrafos que chegam a ocupar a página inteira, frases na ordem inversa e com vários apostos que exaurem o leitor, considero que a qualidade do texto pode ser mensurada pela fluidez na leitura e a facilidade de compreensão. Isso não significa banalizar o conhecimento, mas o contrário, tornar acessível o saber.

\section{Sob pressão}

Para desempenhar as funções de editor é essencial ter autonomia. O editor deve ter livre decisão, sem se curvar aos caprichos e vontades dos donos ou patrocinadores do periódico nem às solicitações explícitas ou veladas dos nomes eminentes na área de atuação. Jamais o editor deve se permitir ser coagido a aceitar trabalhos que considere que não mereçam ser publicados, seja por seus critérios de avaliação ou pelo parecer dos pares que o analisaram. E, saibam os leitores, essa pressão existe e é constante.

Não faltam autores descontentes que usam a amizade ou proximidade aos donos e patrocinadores para passar por cima do editor, pedir sua cabeça ou mesmo "pequenos" favores "que se dê um jeitinho" - porque o autor "precisa muito" que seu trabalho seja aprovado - ontem. Nesses casos, muitas vezes, o editor é interpelado por gente que procura assustá-lo, evocando 
autoridade e inquirindo sobre o porquê da decisão de rejeitar o manuscrito. Para essas situações nada mais simples e salutar do que apresentar as normas editoriais que embasaram a recusa do trabalho.

Em relação e isso é necessário afirmar que as normas editoriais são a arma do editor frente a situações que podem atentar contra a ética editorial. Por isso, devem ser pensadas com extrema cautela, sopesando as circunstâncias que poderiam evocar a excepcionalidade, adotando os critérios definidos pelas instituições que avaliam os periódicos e, inclusive, princípios constitucionais (Brasil, 1988, art. 1ㅜ, 3 , 4º), para estabelecer critérios de fácil compreensão, que eliminem qualquer possibilidade de sobreinterpretação pelos autores. À medida que as situações em que o editor consegue refutar pedidos espúrios, com base nas normas editoriais, conquistará cada vez mais autonomia, pois terá demonstrado que suas decisões não são dominadas por critérios pessoais ou rivalidades acadêmicas, que darão vantagem a um ou outro, mas por regras baseadas na normalização da área e em princípios éticos, definidas e divulgadas a priori, que devem ser acatadas por todos que pretendem publicar no periódico.

Também não é incomum receber telefonemas de autores cobrando providências, agilidade, inclusive em horário de almoço, finais de semana e feriados. Mesmo que a resposta automática de sua caixa de mensagens avise "estou de férias", não falta quem peça que você "dê uma olhadinha no artigo só para ver se está bom antes que eu submeta à publicação". Aconselho a quem pretende enveredar na profissão a nunca atender tais pedidos, que sempre se multiplicarão e ainda poderão colocar em risco a idoneidade do periódico.

Assim, do elogio à coerção, o editor encontrará vários dispositivos que tentam cercear sua autonomia. É indispensável, entretanto, não ceder. Manter a independência bem como as normas de publicação do periódico são estratégias fundamentais para cumprir a função de maneira irrepreensível. O alicerce deste ofício é a ética, que não admite fake news ou narrativas midiáticas. Caso se veja forçado a transigir é melhor deixar o cargo porque junto com seu currículo acadêmico, a imparcialidade ilibada na condução dos trâmites editoriais é o que garante o respeito da comunidade científica ao editor e, consequentemente, o êxito do periódico.

\section{O fazer em si}

Como optei por priorizar a comunicação e o aspecto educativo da prática editorial e considerando que ainda não há definição acerca de como desempenhar a função decidi que seria conveniente "por as mãos à obra", literalmente. Isto significou que a leitura crítica inicial sempre foi feita incorporando pedidos de alterações e sugestões para a melhoria do texto. Tais acréscimos se estendiam da recomendação de leitura de bibliografia adicional, à correção na apresentação de conceitos, indicação de erros metodológicos, passando por revisões semânticas e ortográficas e pedidos de reexame de dados e resultados. 
Se no início simplesmente editava, e o autor que verificasse onde seu texto foi alterado, rapidamente verifiquei que esse método atrasava demais o trâmite editorial porque tornava necessária a leitura simultânea dos dois documentos pelo autor, às vezes apenas para encontrar uma vírgula ou quebra de parágrafo. Assim, paulatinamente, fui adotando ao longo dos anos um sistema de notação para a comunicação com os autores. Busquei critérios bem intuitivos, que reportam ao significado das cores em nossa cultura, considerando ainda os parâmetros dos corretores de texto de alguns programas de edição. Quando necessário essas marcas eram acompanhadas de explicações, especialmente nos casos em que o autor precisava entender o que estava sendo considerado incorreto ou o que precisava ser revisto e acrescentado. De qualquer forma, o trabalho era devolvido ao autor com mensagem inicial, na qual eram apontadas novamente todas as alterações, de modo que ficasse explícito o que havia sido feito e o que se exigia que fosse modificado.

Todas as mudanças que fazia no texto original, seja porque o texto não estava bem escrito, mas a ideia era boa, seja porque se revelava repetitivo e passível de edição, marcava com a cor verde. O verde, da natureza e dos sinais de trânsito, transmite a ideia de harmonia, segurança, tranquilidade. Usava essa cor para indicar desde sinais de pontuação a palavras isoladas, incluindo frases e parágrafos inteiros. Com isso os autores sabiam exatamente o que havia sido alterado e tinham condição de julgar se eu tinha interpretado corretamente o que pretendiam dizer e se tais modificações melhoravam ou pioravam seu texto.

Logo percebi que esse artifício didático não podia ser aplicado indiscriminadamente. Cálculos, taxas, porcentagens incorretas, ou mesmo frases e parágrafos incompreensíveis, mesmo frente a reiterados esforços de leitura, devem ser revistos pelo próprio autor. Não cabe ao editor descobrir por que em determinado caso $2+2=5$ ou o que quer dizer "amostra de conveniência qualificada". Certas peculiaridades, inconsistências e confusões devem ser explicadas pelo autor, que precisa entender exatamente o que quer dizer e tentar redigir de novo. Às vezes são necessárias grandes modificações. Em outras, basta dividir a ideia em frases diferentes, para revelar o que se tem a dizer. Nesses casos, marcava o trecho de vermelho, relembrando as professoras primárias de antigamente, o que incutia nos autores a noção de que realmente precisavam fazer aquelas alterações.

Mas nem só de alterações é feita a leitura crítica inicial da edição científica. Com o advento do control $+C$ control $+\mathrm{V}$ é comum encontrar trechos copiados de outros trabalhos, científicos, de ficção, jornalísticos ou até mesmo de propaganda. Atualmente existem vários programas de detecção de plágio que, aconselho, devem ser usados antes da edição inicial para poupar tempo e vexame ao editor. Mesmo sem eles, fique atento se encontrar no mesmo parágrafo trechos bem escritos e outros de difícil compreensão. Isso pode ser sinal de que o autor não resistiu à tentação de copiar. 
Por incrível que pareça até hoje muitos trabalhos trazem cópias literais de frases ou parágrafos ou fazem pastiche de partes de diferentes textos (Diniz e Terra, 2014: 41). E isso não acontece apenas com estudantes de graduação, que usam seu desconhecimento das regras para justificar a fraude. Mestres e doutores também copiam sem pudor. Esse tipo de situação não deve ser tolerada, mesmo que o texto em questão tenha sido escrito pelo acadêmico mais conceituado da área ou até por autoridade política. Cópia é sempre plágio; não tem justificação. A única forma admissível de utilizar trechos de trabalhos próprios ou alheios é a citação.

Além do plágio o editor deve estar atento porque os autores repetem frases ou trechos do próprio trabalho que estão apresentando dando a sensação de déjà vu, que desmerece o manuscrito e desmotiva o leitor - “de novo? Já não li isso?! Nesses casos optei por marcar o trecho em laranja, não apenas pelo aspecto "fraudulento" relacionado à cor, mas porque sendo próxima do vermelho indica a necessidade de mudança, embora com menos ênfase, atenuando a sensação de recriminação. Às vezes a repetição é inocente; na ânsia de transmitir a ideia a pessoa não percebe que é desnecessária.

Ainda que não seja tão frequente é preciso falar também sobre a questão do autoplágio, quando o autor tenta publicar novamente o mesmo trabalho, alterando o nome do manuscrito ou nem isso. Mesmo com uma pesquisa superficial é possível verificar que antes do advento da internet essa prática era bastante comum em algumas áreas, justificada pela necessidade de dar visibilidade ao conteúdo. Mas, atualmente, quando se pode obter com facilidade todos os trabalhos publicados por um autor, não há mais razão para a publicação repetida. A questão se torna mais delicada ainda porque ainda não existe definição exata do que seria o autoplágio.

Considerando a facilidade de encontrar o mesmo texto publicado em diferentes periódicos, poderíamos decidir que o autor não pode usar trecho de trabalho que já tenha publicado. Nesse caso, terá que elaborar a ideia novamente? Acredito que o editor não deve impedir que o autor utilize trabalhos anteriores, entretanto, devem aparecer apenas como citação, com número de referência e todas as informações pertinentes à publicação original no campo definido para apresentar a bibliografia (notas de rodapé ou de fim). Trabalhos anteriores podem ser usados para apoiar novas proposições, que demonstrem o desenvolvimento intelectual do autor, mas devem resguardar sempre a questão do tamanho do texto reproduzido e a identificação da primeira publicação. Não vale apresentar o mesmo texto, ipsis litteris, como se fosse produção original. Isso também é fraude.

Por fim usei a cor roxa para indicar os trechos que deviam ser suprimidos, utilizando-a tanto para marcar os identificados como autoplágio, que teriam que ser transformados em citação, quanto explicações desnecessárias aos propósitos do manuscrito. Esse último tipo de situação ocorre frequentemente em trabalhos de autores que acabaram de entrar em contato com a gênese e a história da área, e que, portanto, acham muito importante repetir aqueles fatos que, no entanto, já são amplamente conhecidos. É como ter que explicar a pangeia para falar da 
invasão do Brasil pelos portugueses em 1500. Mesmo considerando a importância de fomentar o caráter didático da publicação, esse tipo de informação repetitiva cansa o leitor mais qualificado e infantiliza o periódico, sendo classificada como redundante. Assim como os autores tiveram acesso a ela outras pessoas também já as conhecem. Por isso, elimine.

Se ao começar a exercer a função eu temia que os autores reclamassem muito das alterações, fui descobrindo com o tempo que alguns sequer as notavam ou, ao menos, aceitavam sem tocar no assunto. Essa foi uma das razões para adotar a cor verde para as modificações que fazia, garantindo que as mudanças tinham sido vistas e que o autor concordava (ou não) com elas. Conforme fui utilizando as marcas e padronizando o cuidado com as explicações, passei a receber não os protestos que temia, mas profusos agradecimentos. De fato, durante todo período que exerci a função publicando em torno de 800 manuscritos e editando ainda mais apenas um autor retirou seu trabalho, descontente com a edição inicial. Tal resultado me levar a considerar que valeu à pena o esforço para desenvolver o método de trabalho focado na comunicação acessível entre quem escreve e quem lê os artigos.

\section{Por que Antropologia?}

Quem acompanhou o texto até aqui deve estar se perguntando, afinal de contas, qual a relação entre a tarefa de editar e a Antropologia? De fato, ao receber o convite para produzir este texto pensei sobre o assunto, chegando até a pensar em desistir por considerar que a formação não se relaciona diretamente com o fazer editorial. Entretanto, durante esses 12 anos recorri às ferramentas metodológicas aprendidas na graduação, principalmente, a capacidade de identificar padrões, exercitar o distanciamento em relação ao campo e separar a análise das condutas padronizadas dos comportamentos e valores sociais, introjetados e reproduzidos no cotidiano.

A percepção da necessidade do distanciamento como ferramenta para o exercício da função de editora, é uma dessas habilidades. Essa importante ferramenta metodológica permitiu ser e trabalhar em situação peculiar e delicada: numa sociedade complexa contemporânea, analisando práticas e serviços profissionais dos quais eu mesma sou objeto, mas, como não pertenço à "categoria profissional dos médicos" [em linguagem nativa] nunca poderia me igualar a eles em decorrência da percepção de valor que eles têm de si mesmos.

Ser médico é considerado pela maioria desses profissionais como sua principal identidade, uma atribuição que os torna mais do que simples humanos, com capacidade quase divina de recuperar a vida. Um "sacerdócio" que encanta os neófitos pela possibilidade de conferir o dom da cura por meio do conhecimento: de sua técnica e ética. A representação benevolente, entretanto, oprime os que já estão envolvidos na prática e percebem a enormidade inexpugnável da tarefa. 
A autopercepção dos profissionais de valor superior enquanto categoria profissional é quase que onipresente na Medicina. Ela se transfere do profissional para o indivíduo, modulando todas as suas inter-relações. Entre si, os profissionais se consideram tão importantes que menosprezam a capacidade de diferentes áreas da própria Medicina e outras áreas da Saúde. Em geral, quão mais invasiva a práxis mais poderoso o profissional. A sensação de superioridade em relação àqueles com quem trabalham no cotidiano aprofunda-se e alarga-se exponencialmente quando comparada ao conhecimento gerado nas outras áreas. $\mathrm{O}$ ethos da Medicina se baseia na crença dos médicos, convictos que sabem mais do que todas as outras pessoas, de toda e qualquer área do conhecimento ou mesmo na vida social.

Como toda e qualquer coisa no universo, esse aspecto inerente à medicina traz consequências boas e nefastas, para os profissionais e para sociedade. Durante a pandemia de covid-19, que estamos enfrentando em 2020 e 2021, por exemplo, o ímpeto de usar seu conhecimento em prol dos outros possibilitou a indiscutível dedicação dos profissionais de saúde, nas frentes de trabalho e na pesquisa. Foi esse empenho que tem permitido à sociedade brasileira sobreviver ao tsunami da pandemia, especialmente nesse barco sem rumo que se transformou o país.

Não há como negar que sem a dedicação dos profissionais de saúde, e não apenas dos médicos, teria sido impossível passar por essas fortes turbulências. Mesmo sucateado, mal assistido e depreciado, o Sistema Único de Saúde (SUS) demonstrou seu valor ao minimizar a vulnerabilidade da população frente à pandemia, facultando, à medida do possível, o acesso ao tratamento hospitalar e à vacinação aos mais carentes. Não é demais sublinhar que o SUS foi na prática - a grande conquista democrática advinda da Constituição de 1988 (Brasil, 1988, art. 196).

Mas o preço dessa dedicação, a nível pessoal, é alto. Vivenciando a perda de pacientes cotidianamente os profissionais se deparam muito mais com a morte, aguçando angústia e temor. O cansaço também cobra sua parte, concorrendo para a somatização do estresse físico e mental. Piora a situação a falta de perspectiva de mudança no quadro, seja porque a população insiste em se aglomerar propagando a doença, tanto por necessidade de sobrevivência quanto por desejo de prazer, seja porque a vacinação segue em ritmo lento, “devagar quase parando", por falta de empenho do governo em assegurar insumos e vacinas.

O esforço para enfrentar a situação foi destilado na coragem dos profissionais que não se furtaram a essa batalha cotidiana e inglória, mesmo se defrontando com o perigo, amplificado pela desinformação propalada pelo governo federal sobre a pandemia e suas formas de prevenção, somada à falta de equipamentos e de medicamentos para atender a demanda crescente da população. É importante assinalar a atuação nefasta do governo e da instância federal que regula a prática da Medicina (Conselho Federal de Medicina - CFM), promovendo 
a polarização ideológica em relação ao uso de medicamentos, aconselhando a prescrição de kits de prevenção ineficazes e olvidando os indispensáveis para o tratamento.

Sobre esse ponto é preciso reiterar para fim de contextualização histórica, que vivemos desde 2019 sob os desígnios de uma autoridade federal que não parece interessada no bem comum e dirige o país sem olhar para as reais necessidades da população; sem ouvir a ciência ou sequer o simples bom senso. Um governo que banaliza a sobrevivência individual e coletiva, considerando-a simples produto da luta entre fracos $\mathrm{x}$ fortes, maricas $\mathrm{x}$ machos, (BBC News Brasil, 2020). Cabe apontar ainda que as restrições orçamentárias imputadas pelo governo anterior ao orçamento da Educação e da Saúde (Agência Câmara De Notícias, 2017), também cobraram consequências adversas no enfrentamento da pandemia.

Não posso deixar de reconhecer que a autopercepção desses profissionais ajudou a construir o distanciamento necessário ao trabalho de campo, que incluía o fazer editorial. Para eles eu era, indiscutivelmente, o outro (Balandier, 1987). Considero que nos 12 anos que trabalhei como editora em periódico de bioética produzido pelo CFM estive em trabalho de campo, de maneira assistemática, analisando as condutas sociais e o comportamento público dos integrantes do Conselho e dos que compunham suas várias comissões, entre si e com os funcionários da casa, bem como as resoluções que aprovavam, cassavam e reeditavam. Como para muitos deles é impossível que alguém que não seja médico possa igualá-los, já que os leigos não "possuem o conhecimento sobre manter a vida".

Salvo raras exceções, quando não falam entre si, os médicos sempre se dirigem ao "outro", que, em geral, está hierarquicamente abaixo deles, por ser paciente ou simplesmente leigo. Ainda que a bioética clínica venha discutindo há quase seis décadas a noção de autonomia do paciente, verifica-se que ainda é difícil para os profissionais encontrar o equilíbrio entre a proteção à vulnerabilidade (Schramm, 2008) e respeito ao direito à autonomia. Cito essa situação peculiar não porque seja relevante para qualquer editor em qualquer área e sim para exemplificar como foi importante compreender o campo de pesquisa e os "nativos" com os quais trabalhava. Como fui criada em uma sociedade que valoriza o saber médico e confere-lhe status superior e tendo sido contratada por uma corporação médica percebi que era fundamental observar a perspectiva dos profissionais da saúde com o distanciamento necessário para perceber seus valores, mas sem incorporá-los.

A consciência de que se está em campo é indispensável para entender com quem se fala. Adotar linguagem acessível ao leitor é tarefa essencial no trabalho de editar. Claro que se o editor trabalha em sua área de formação essa adequação da linguagem é mais simples, afinal a comunicação é endereçada a público que partilha seu "dicionário”, seu arcabouço teórico, código moral ou mesmo suas ideias. Quando o editor se dirige ao público cuja área de formação distinta é preciso aprender o jargão nativo tanto na teoria quanto na prática, como em qualquer trabalho de campo em outra cultura. 
É necessário também estudar, ainda que superficialmente, o conhecimento da área e, mais profundamente, sua história, conhecendo as análises e críticas sobre seus processos e dispositivos. Além do saber teórico é essencial fazer trabalho de campo em diferentes situações de pesquisa na área em que se vai atuar como editor (pesquisa de campo, avaliação de políticas públicas e programas, análise e consolidação de dados em pesquisa multicêntrica, etc). Esse background é importante para a atuação profissional.

Mas nem só de conhecer as palavras, saber como utilizá-las, cortá-las ou adequá-las é feita a atividade editorial. Não basta trocar palavras grandes por sinônimos menores, buscar a ordem direta das frases, eliminar vícios de linguagem, como o uso exacerbado do artigo, especialmente dos indefinidos, as confusões no uso dos advérbios (principalmente entre tempo e lugar) ou as incorreções semânticas e ortográficas. $\mathrm{O}$ editar em si também diz respeito aos termos que o editor nunca usaria, mas que percebe que são importantes para o autor e por isso se dispõe a melhorar a compreensão de trecho do manuscrito apenas para mantê-los. Da mesma forma que há termos desnecessários e trechos repetitivos, existem palavras que, mesmo não sendo conceitos, organizam a linha de pensamento do autor ou, as que por qualquer idiossincrasia considera desejável manter. Acho que essa compreensão decorre do feeling antropológico, o colocar-se na pele do autor para destrinchar qual o peso que dá às palavras que usa.

Para facilitar a compreensão vou citar termos neste texto, que poderiam facilmente ser trocados por sinônimos mais acessíveis, facilitando a leitura. São estrangeirismos ou termos que estão caindo em desuso como furtiva, esquadrinhadora, pernósticos, vetusta, métier, frisson, sobreinterpretação, ilibada e deveras. Todos surgiram espontaneamente durante o processo de redação, mas só foram mantidos na versão final do texto com o propósito de ilustrar com exemplo palpável a afirmação acima. De que é tão importante identificar o que deixar no texto quanto o que cortar para não expropriar o autor de sua criação. De certa forma, é como reproduzir o elemento essencial da fala nativa.

Para conseguir essa identificação, novamente, pude contar com técnicas da Antropologia. Além da óbvia caracterização por área da Saúde, enfermagem, medicina, fisioterapia, psicologia, nutrição em seus diferentes graus de formação, se pode observar também alguns tipos padrões nos relatos. A experiência vai permitindo conhecer e correlacionar certos tipos de escrita, possibilitando identificar características dos autores. Grupos de professores e alunos de graduação; de orientadores e orientandos; orientadores, membros de banca e doutorandos ou mestrandos; trabalhos de grupos de estudo de alunos de graduação ou pós-graduação, de núcleos de pesquisa etc. Não que esses grupos apresentem características únicas, similares e inequívocas. Mas combinando a área de formação com a composição do grupo é possível entrever quem de fato escreveu o trabalho, se foi uma ou foram várias pessoas, 
se trabalharam em conjunto, se dividiram o trabalho em partes entre si ou se um deles se encarregou da maior parte das tarefas.

Reconhecer esses padrões não tem muita utilidade prática no momento em que se está editando. Mas ajuda muito a entender qual a melhor forma de se comunicar com os autores. Que tipo de exigência se deve ou pode fazer (porque às vezes não adianta exigir dos autores não conseguem fazer) e para quem. Auxilia o editor a decidir se vale à pena sugerir bibliografia adicional ou mesmo apontar outra perspectiva analítica. Contribui para compreender se os autores querem ouvir e entender ou se já são copos cheios até a borda de certezas.

Percebi, por fim, que a comunicação entre editor científico e autores acontece quando se consegue estabelecer a justaposição de ideias. Quando há troca. A riqueza da atividade advém do contato íntimo com a produção de muitos atores, de profissões, nível de formação, atividade, região geográfica e instituições diferentes, as quais é preciso entender para conseguir dialogar. Desta forma, o processo solitário de escrever ganha eco e se difunde na dimensão social, como uma onda capaz de influenciar visões de mundo e contribuir com a formação no campo de estudo.

\section{Enfim, a edição do campo}

As ideias, conceitos, as categorias e até mesmo o sentido último das palavras precisam ser constantemente estudadas, formuladas, apresentadas e repetidas. Só assim o fazer cotidiano do editor se torna vivo, entranhado na comunidade acadêmica e profissional para a qual dedica seu trabalho. Só a atenção contínua e detalhada às ideias e conceitos pode transformar a percepção, alterar parâmetros, corrigir enganos, contribuindo para o aperfeiçoamento das técnicas e ferramentas analíticas. A edição científica também colabora para registrar o estado da arte e a história do campo de estudo.

Acho justo salientar que me parece que a satisfação com a atividade de editor científico, quando esta cumpre todos os requisitos aqui apresentados - paixão pela leitura e escrita, o desejo por liberdade, a luta pela autonomia, a dedicação à formação, é (ou deveria ser) razão suficiente para seduzir alguém com formação em Antropologia a ousar seguir por esta trilha, que leva a campos de pesquisa que se precisa explorar de maneira diferenciada, mas capaz de responder aos anseios de compreensão do mundo de quem se devota a essa formação.

Para mensurar acertos e erros o editor contará com indicadores como a indexação do periódico em plataformas e bibliotecas de publicação, a avaliação pelas instâncias da Educação que regulam a produção na área, o reconhecimento pelos pares e o acesso dos leitores. Mesmo implicando em algumas (ou muitas) dificuldades esses indicadores são passíveis de obtenção caso o periódico conte com condições para existir (inclusive financiamento) e comumente se traduzem em respeito e consideração ao trabalho do editor. 
Mas além desses indicadores exógenos o editor poderá também sentir-se satisfeito com seu trabalho ao observar o percurso dos autores rumo ao conhecimento, o desenvolvimento de suas reflexões e sua escalada acadêmica. Sempre me senti contente com o sucesso daqueles cujos primeiros textos editei enquanto ainda eram estudantes de graduação, com os quais mantive contato por meio da edição de manuscritos durante o mestrado e o doutorado. Em alguns casos, cheguei a receber trabalhos destas mesmas pessoas, agora com os títulos de mestres e doutores, atuando como professores e orientadores de seus próprios alunos.

Ter a oportunidade de acompanhar o processo de formação de estudantes de todo país e contribuir com ele, na medida do possível, é o grande trunfo desta atividade, que permite o debate no plano das ideias e propicia renovar a esperança num futuro mais justo e menos desigual. Porque amanhã depende do que investimos hoje na Educação, que precisa ser a meta do país, o objetivo das instituições de ensino e pesquisa, o trabalho cotidiano de professores, estudiosos e pesquisadores, e o desejo insubstituível da sociedade na busca de sua independência e emancipação.

\section{Referências bibliográficas}

AGÊNCIA CÂMARA de NOTÍCIAS. 2017. Michel Temer sanciona projeto da Lei de Diretrizes Orçamentárias para 2018 com vetos. Disponível em: https://www.camara.leg.br/noticias/520060-michel-temer-sanciona-projeto-da-lei-dediretrizes-orcamentarias-para-2018-com-vetos/ acesso 27/04/2021 acesso 27/04/2021

BALANDIER, Georges. 1987. Antropo Lógicas. São Paulo: Cultrix. p. 61.

BBC News Brasil. 2020. "País de maricas" e outras 15 falas controversas de Bolsonaro sobre a pandemia. O presidente brasileiro, Jair Bolsonaro, tem mantido uma média mensal de ao menos uma declaração controversa ou anticientífica sobre a pandemia de coronavírus. Disponível em: https://www.youtube.com/watch?v=unjwCA9RdSk acesso 27/04/2021

BEAUCHAMP, Tom L; CHILDRESS, James F. 2002. Princípios de ética biomédica. (4 a ed.) São Paulo: Edições Loyola. Nova York: Oxford.

BOURDIEU, Pierre. 2012. O poder simbólico. Rio de Janeiro: Bertrand Brasil.

BRASIL. (1988). Constituição da República Federativa do Brasil. Brasília: Senado Federal.

DINIZ, Débora; TERRA, Ana. 2014. Plágio: Palavras escondidas. Brasília/Rio de Janeiro: Letras Livres/Editora Fiocruz. p.41-45.

MERLO, Ivanésio. 2012. "Editorial - Das origens das revistas científicas ao Jornal Vascular". Jornal Vascular Brasileiro, vol. 11, n. 2, p. 93-94. DOI https://doi.org/10.1590/S167754492012000200002 
PORTO, Dora. 2010. "Relato de uma experiência concreta com a perspectiva das ciências da saúde: construindo o anthropological blues". In: FLEISCHER, Soraya; SCHUCH, Patrícia. Ética e regulamentação na pesquisa antropológica. Brasília: Letras Livres/Editora UnB. p. 101-126. SCHRAMM, Fermin Roland. 2008. "Bioética da proteção: ferramenta válida para enfrentar problemas morais na era da globalização”. Revista Bioética, vol. 16, n.1. p. 11-23.

SILVA, André Felipe Cândido da. "Carta do editor: A história e as mudanças na publicação científica: resistência ou adaptação?” História, Ciências e Saúde - Manguinhos, vol. 26, n. 3 DOI https://doi.org/10.1590/s0104-59702019000300001

UNESCO - Organização das Nações Unidas para a Educação, a Ciência e a Cultura. 2005. Declaração Universal sobre Bioética e Direitos Humanos. Paris: UNESCO. Disponível em: https://unesdoc.unesco.org/ark:/48223/pf0000146180_por acesso 27/04/20021.

sobre a autora

\section{Dora Porto}

É graduada em Ciências Sociais com habilitação em Antropologia, especialista em Bioética e doutora em Ciências da Saúde, área de concentração Bioética, pela Universidade de Brasília. Atuou em pesquisa de campo no Núcleo de Estudos e Pesquisa sobre a Mulher (NEPeM/ UNB) e no Núcleo de Pesquisa sobre Saúde Pública (NESP/UnB). Foi fundadora e desempenhou as funções de editora executiva na Revista Brasileira de Bioética, sendo também editora científica da Revista Bioética.

Contribuição de Autoria: Não se Aplica

Financiamento: Não se Aplica

Recebido em 7/04/2021

Aceito para publicação em 14/06/2021 